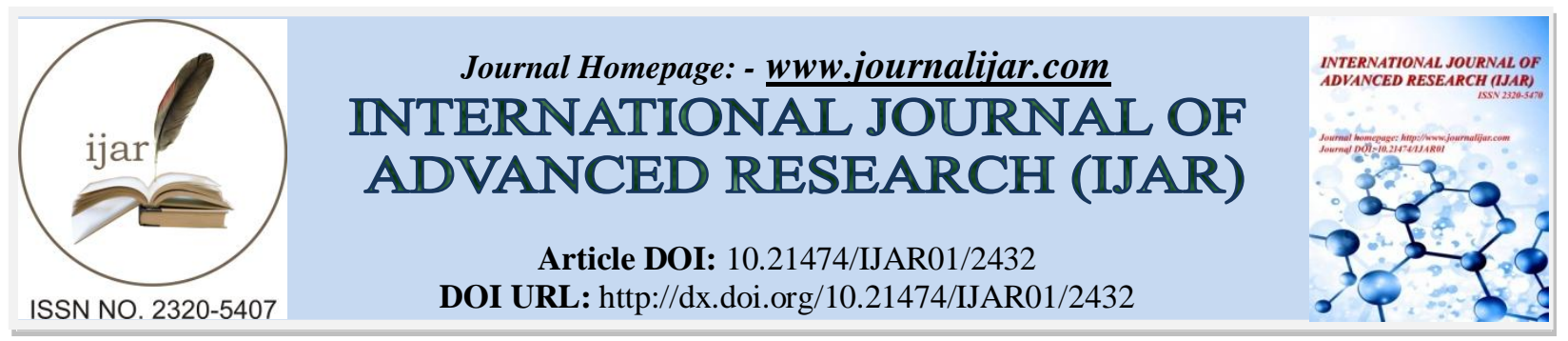

RESEARCH ARTICLE

\title{
THE EFFECT OF GENDER ON CHOOSING RADIOLOGY AS A CAREER AMONG MEDICAL STUDENTS AND INTERNS IN SAUDI ARABIA.
}

Al Qahtani Talal, Al Gosi Sarah, Al Anazi Amnah and Al Hasan Mustafa.

\section{Manuscript Info}

\section{Manuscript History}

Received: 20 October 2016

Final Accepted: 22 November 2016

Published: December 2016

Key words:-

Gender, Radiology, Preference career,

Saudi Arabia.

\section{Abstract}

Background:- In regards to radiology, according to recent statistics and studies, the numbers of male radiologists actively involved in the specialty have always been greater compared to female radiologists in international institutions worldwide.

Objectives:- To determine whether there is a difference between males and females in choosing Radiology as a career choice in Saudi Arabia and the reasons behind making the decision.

Materials and methods:- A cross-sectional study was carried out. A questionnaire was formed and established electronically on https://www.surveymonkey.com/s/radiologycareer. The questionnaire was anonymous and targeted medical students and interns in all universities in Saudi Arabia. And they asked about factors contributed on choosing radiology as a career. The results were stratified by gender.

Results:- The study included 404 students. A $46.8 \%$ of male students compared to $16.3 \%$ of female will choose Radiology as a future career, $\mathrm{p}<0.001$. More than one quarter of male students $(26.6 \%)$ compared to $17.9 \%$ of female students reported that, Radiology as being not a surgical specialty had affected their decision. The difference was statistically significant, $p=0.037$. Exactly half of female students compared to only $5.7 \%$ of male students agreed that the social life in Saudi Arabia played a role in making their decision in career choosing. About two-thirds of female students (65.9\%) compared to $41.4 \%$ of male students considered the limitation of oncall hours as a factor to making their decision, $\mathrm{p}<0.001$. Similarly, $63.4 \%$ of female students and $28.5 \%$ of male students considered the exposure to Radiation played a role in making their decision, $\mathrm{p}<0.001$. For females, considering future pregnancy has affected decision was reported by $64.6 \%$ of them.

Conclusion:- There is a significant difference between male and female medical students in choosing Radiology as a future career. They differed somewhat in the importance they put on about motivational factors. 


\section{Introduction:-}

The gender differences have always been present worldwide in several medical specialties. Females are often more drawn to certain specialties than others. According to the Association of American Medical College AAMC's 2008 physician specialty data, females constituted $44.6 \%$ of the total of active residents/fellows in Accreditation Council for Graduate Medical Education (ACGME) accredited programs, while men constituted 55.4\% of the total. With the percentages almost reaching to equal proportions yet major variations where cited on their distribution among specialties. Female medical residents constituted more than 50\% of the total in pediatrics and up to 50\% in internal medicine/pediatrics and child \& adolescent psychiatry. Surprisingly, females constituted almost $20 \%$ of the total in radiology and ophthalmology with the percentages declining down to 5\% of the total in other specialties including; urology, orthopedic surgery and neurological surgery. ${ }^{[1]}$ More recently, according to the College AAMC's 2012 physician specialty data, females constituted $46.1 \%$ of the total of active residents/fellows in ACGME accredited programs, while men constituted $53.9 \%$ of the total. With an increase of $2 \%$ in favor of female medical residents over the period of 4 years, females constituted more up to $60 \%$ of the total number of residents in pediatrics and with percentages reaching up to 50\% in internal medicine/pediatrics, child \& adolescent psychiatry and obstetrics and gynecology. Meanwhile, radiology and ophthalmology showed the same percentages seen in 2008. Specialties including; urology, orthopedic surgery and neurological surgery remained male dominant. ${ }^{[2]}$

A study conducted in Japan 2009, showed a preference of male medical students for general surgery, orthopedics, neurosurgery, and emergency medicine, while female medical students showed a preference for obstetrics \& gynecology, pediatrics, and dermatology. ${ }^{[3]}$ These findings correspond with the statistics mentioned previously by the AAMC. Though with favors for males in regards to surgical specialties, females believe that surgical specialties are not welcoming careers. This is due to difficulties in maintaining family life, limited flexible training and lack of role models according to a recent study in Nottingham University Hospital, United Kingdom 2012. ${ }^{[4]}$ Similarities were observed in a study done in the University of Nairobi, Kenya 2010, the study found that male medical students were drawn more to surgical specialties, while female medical students were drawn more to pediatrics proving that there is a gender difference upon choosing a specialty in medicine. ${ }^{[5]}$ A recent Swedish study in 2013 done among medical students found that females preferred pediatrics and obstetrics and gynecology over other specialties compared to male medical students. ${ }^{[6]}$

With gender differences being proved by several studies, it raises the question as to why females prefer certain specialties over others. An Israeli study conducted in 2012 among medical students found that male medical students were more interested in well-remunerated procedure oriented specialties that allowed for private practice. Meanwhile, female medical students preferred shorter residencies with few on-calls and limited hours. ${ }^{[7]}$

Currently, there is no available data whether female medical students are more open to a career in radiology in Saudi Arabia and what would be the reasons behind pursuing it. This study aims to investigate the gender differences in choosing a career in radiology. It will also investigate the factors of most importance in making the decision to follow a lifelong career in the specialty.

The purpose of this study is to determine whether there is a difference between males and females in choosing Radiology as a career choice in Saudi Arabia and the reasons behind making the decision.

\section{Materials and Methodology:-}

A cross-sectional study was carried out. A questionnaire was formed and established electronically on https://www.surveymonkey.com/s/radiologycareer. The questionnaire was anonymous and targeted medical students and interns in all universities in Saudi Arabia. The link was distributed with the help of the representatives of each university on a social network group known as Medical Students in Saudi Arabia (MSSA) which gathers near to 10,000 medical students from different universities. It was also distributed in social networks including (twitter, Facebook, etc...). A total of 25 questions were administered, consisting of 19 yes and no questions. The participants were asked to supply their telephone and university number optionally for a random poll of an iPad-Mini for their support and participation in our research. We targeted a large sample of medical students from 400-500 participants.

The research proposal was accepted by department of Radiology at the University of Taibah, Medina. The participants consisted of 2 teaching assistants from 2 different universities and 2 radiology residents from 2 different hospitals. The participants were formed of 1 lead researcher, 2 research assistants and 1 data analyst. We had a brain 
storming session with the participants of the research. We determined which are the most important factors that affected the decision of medical students to choosing Radiology as a career. After inquiring about; gender, age, university and current level of education 15 factors were identified including 1 that targeted only females. The factors were as follow; intellectual excitement, income, patient contact, radiology not being a surgical specialty, emotional sensitivity, physical inability, use of technology, social life, work hours, work environment, private clinics work, on-call hours, competitiveness, exposure to radiation, and physics. Only one factor that targeted females was pregnancy.

The time frame for the research was given 3-4 months up to the finish line. 2 weeks for establishing a questionnaire and preparing an introduction. 1 month was given for collection of data and 1 month for analysis. 2 weeks were then given for preparation of the results and discussion. 2 weeks were also given for establishing a conclusion and recommendations. 1 week was for formulation of an abstract.

Data were entered and analyzed using IBM SPSS v21. The lead researcher was the second analyst for confirmation and auditing of the results. Chi-square analysis was used and $\mathrm{p}$ value less than 0.05 were considered as a cut-off level for statistical significance.

\section{Results:-}

The study included 404 students recruited from 20 Universities all over the Kingdom of Saudi Arabia. Most of them were females (60.9\%) as illustrated in Figure 1. Table 1 presents age and academic level distribution of the students. Sixty percent of them aged between 22 and 23 years and $40.7 \%$ were interns.

Table 2 summarizes the difference between male and female medical students regarding different aspects related to choosing of Radiology specialty as a future career. Sixty eight male students (43\%) compared to only 4 female students $(1.6 \%)$ had very good background about Radiology. This difference was statistically significant, $\mathrm{p}<0.001$. Similarly, $46.8 \%$ of male students compared to $16.3 \%$ of female will choose Radiology as a future career, $\mathrm{p}<0.001$. Also, $49.4 \%$ of male students compared to $23.6 \%$ of female students were going to choose Radiology elective rotation during internship, $\mathrm{p}<0.001$. More than one quarter of male students $(26.6 \%)$ compared to $17.9 \%$ of female students reported that, Radiology as being not a surgical specialty had affected their decision. The difference was statistically significant, $\mathrm{p}=0.037$. Majority of female students (87\%) compared to $59.5 \%$ of male students considered Radiology as an intellectually exciting specialty, $\mathrm{p}<0.001$. Exactly half of female students compared to only $5.7 \%$ of male students agreed that the social life in Saudi Arabia played a role in making their decision in career choosing. More than half of male students (59.5\%) compared to $34.6 \%$ of female students agreed that the work environment in Radiology field being the opposite of an ER settings affected their decision, $\mathrm{p}<0.001$. More than half of female students (53.3\%) compared to $22.8 \%$ of male students agreed that the limitation of private clinics work has affected their decision, $\mathrm{p}<0.001$. The income affected decision of choosing future career was reported by $40.2 \%$ and $18.4 \%$ of female and male students, respectively, $\mathrm{p}<0.001$. About two-thirds of female students $(65.9 \%)$ compared to $41.4 \%$ of male students considered the limitation of on-call hours as a factor to making their decision, $\mathrm{p}<0.001$. Similarly, $63.4 \%$ of female students and $28.5 \%$ of male students considered the exposure to Radiation played a role in making their decision, $\mathrm{p}<0.001$. More than one third of male students $(42.4 \%)$ compared to $16.7 \%$ of female students considered that Radiology relied heavily on physics has affected their decision, $\mathrm{p}<0.001$. For females, considering future pregnancy has affected decision was reported by $64.6 \%$ of them.

Table 1:- Age and academic level distribution of the participants $(n=404)$.

\begin{tabular}{|l|l|l|l|}
\hline Variables & Categories & Frequency & Percentage \\
\hline Age & $<21$ & 68 & 16.8 \\
& $22-23$ & 242 & 60.0 \\
& $\geq 24$ & 94 & 23.2 \\
\hline Academic level & First year & 14 & 3.5 \\
& Second year & 14 & 3.5 \\
& Third year & 27 & 6.7 \\
& Fourth year & 44 & 10.9 \\
& Fifth year & 65 & 16.1 \\
& Sixth year & 75 & 18.6 \\
& Internship & 165 & 40.7 \\
\hline
\end{tabular}


Table 2:- Comparison between male and female students regarding preference of Radiology specialty as a future career

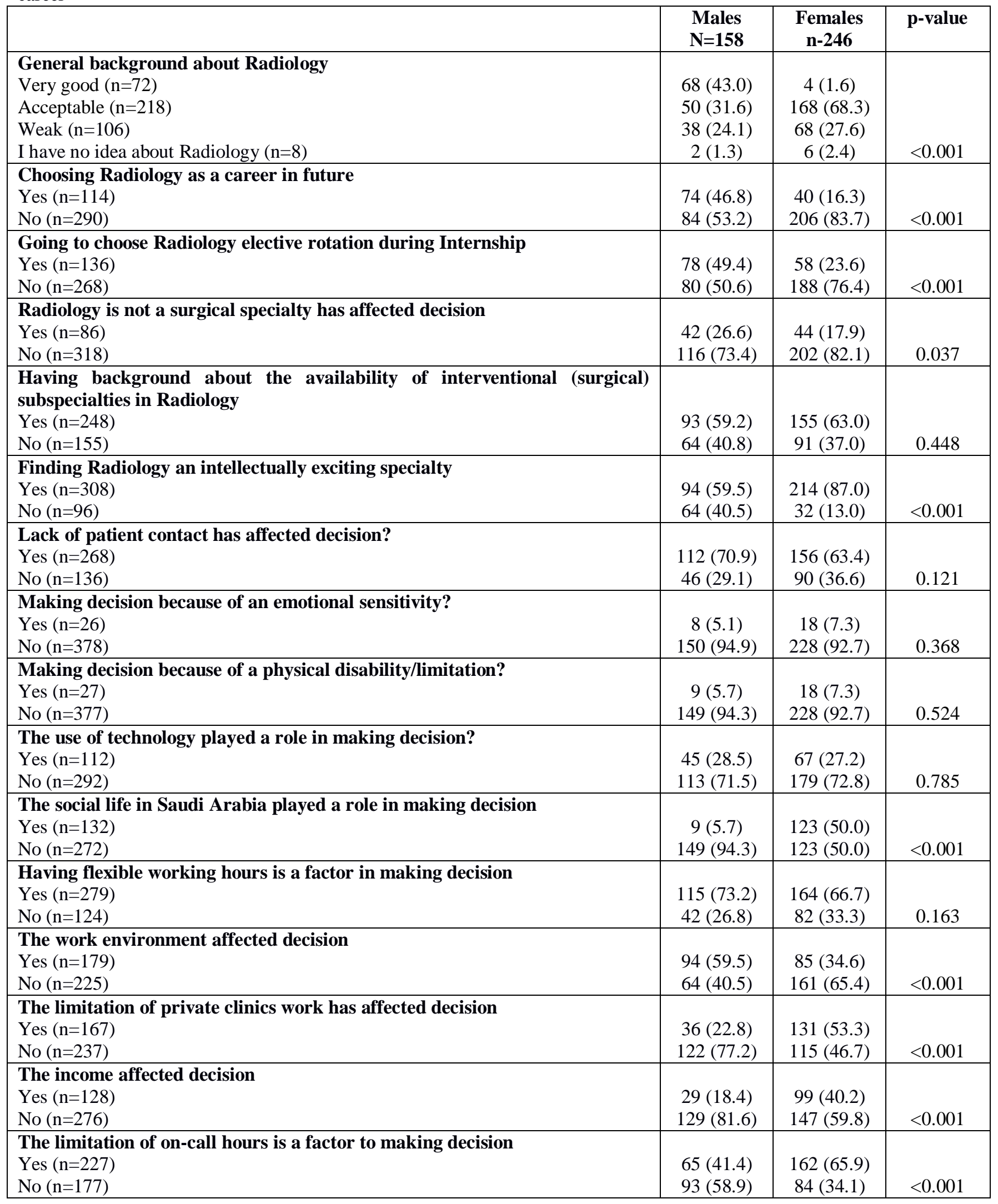




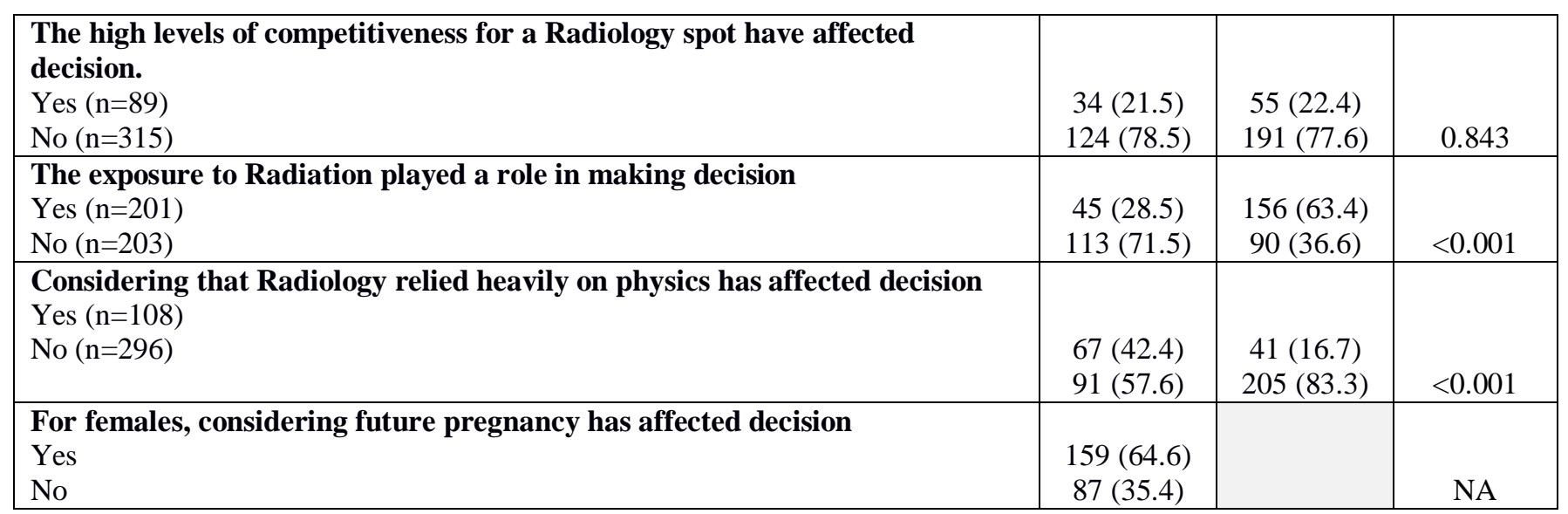

NA: Not applicable

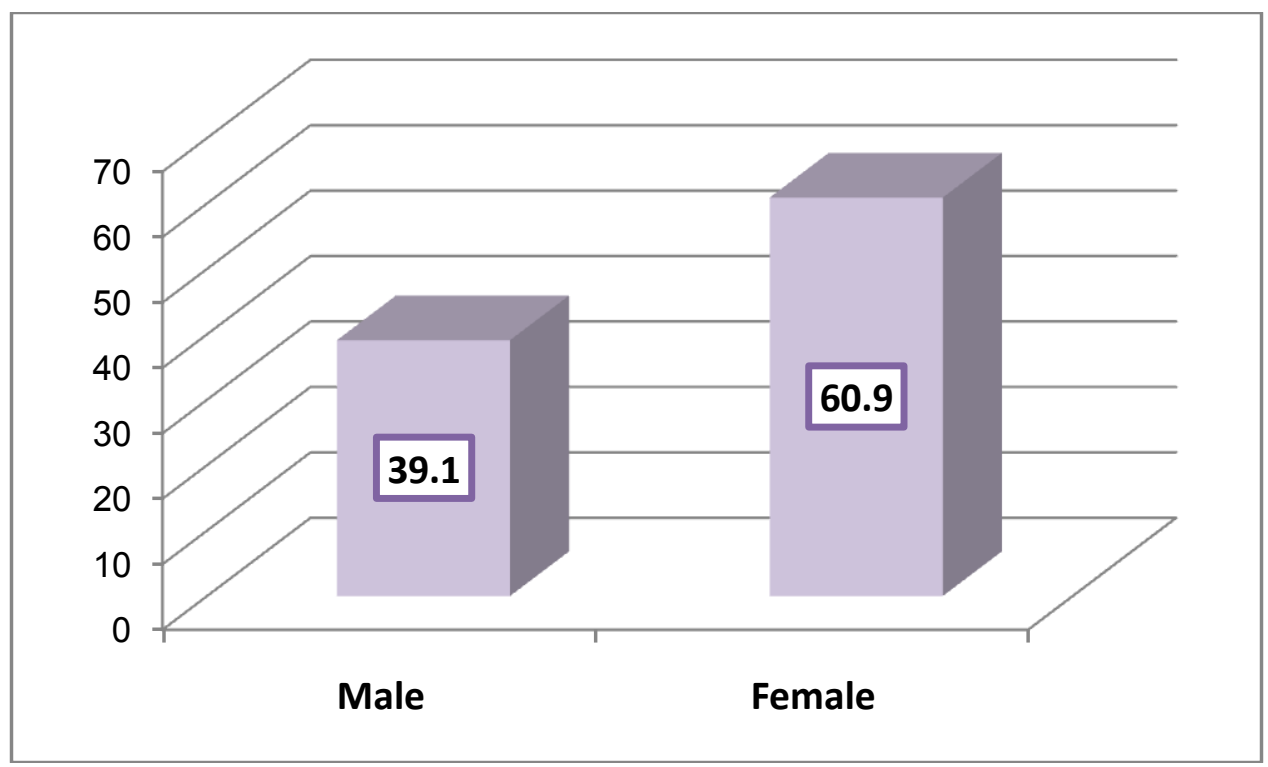

Figure 1:- Age distribution of the participants.

\section{Discussion:-}

Internationally, while the number of female entering medical schools is approaching $50 \%$ and even exceeds, they continue to be underrepresented in a number of specialties including diagnostic radiology although it has many characteristics that might be desirable to females, such as reasonable call hours, flexible scheduling, and high salaries. ${ }^{[8]}$ The present study was done to explore the difference between males and females in choosing Radiology as a career choice in Saudi Arabia and the reasons behind making the decision.

It is obvious from the current study that there is a significant difference between male and female medical students regarding many elements related to choosing Radiology as a future career. More males than females had very good background about Radiology, will choose Radiology as a future career, were going to choose Radiology elective rotation during internship, and reported that Radiology as being not a surgical specialty had affected their decision. On the other hand, more female students considered Radiology as an intellectually exciting specialty, agreed that the social life in Saudi Arabia played a role in making their decision in career choosing than male students.

In North America, women constitute only $25 \%$ of radiology residents, even though they constitute $45 \%$ of medical students. ${ }^{[9]}$ In Japan ${ }^{[10]}$ as well as the U.S ${ }^{[11]}$ and Europe, ${ }^{[12]}$ women accounts for about one third to half of medical students and have become a growing part of medical schools. However, female physicians are still underrepresented in some specialties in these countries including Radiology. ${ }^{[13]}$ Enoch et al. demonstrated that Radiology is among specialties that feature a controllable lifestyle (control of work hours), while non-controllable lifestyle specialties were surgery, internal medicine, family practice, pediatrics, orthopedic surgery, and obstetrics \& gynecology. ${ }^{[14]}$ 
According to the ACGME data resource book of 2011-2012, the total number of radiology residents actively enrolled in a Radiology training program was 4,650 radiology residents. The total number of female residents was 1271 which only constituted $27 \%$ of the total, while the total of male residents was 3,217 constituting $73 \%$ of the total number ${ }^{[10]}$ Surprisingly, according to ACGME statistics of 2004, the female radiology residents constituted only $25 \%$ of the total number of radiology residents. ${ }^{[11]}$ It is very well observed that the percent of female radiology residents increased only by $2 \%$ during the period of 7 years (2004-2011).

In 2003, a study published in the Saudi Medical Journal was performed among interns in King Faisal University found that $89.2 \%$ of male medical students chose radiology as the most popular elective rotation compared to female medical students who chose ENT elective rotations with a percentage of $75 \%$. With higher number of male medical students choosing radiology electives compared to females, the study did not specify the reasons behind making such decision. ${ }^{[12]}$

Though with availability of encouraging factors including; job flexibility, life style and stable work hours which would appeal to female medical students, yet they defer from enrolling into radiology due to lack of direct patient contact, required physics knowledge, and long hours spent working in dark rooms according to a very recent study done in Western University in London, Ontario 2013 (Zener R et al., Presented at the American Roentgen Ray Society (ARRS) meeting 2013). Another study cited that the level of competitiveness is a strong reason behind females dissuading from pursuing a career in radiology. ${ }^{[13]}$

In the current study, male students more agreed than female students that the work environment in Radiology field being the opposite of an ER settings affected their decision and the income affected decision of choosing future career whereas more female students compared to male students agreed that the limitation of private clinics work has affected their decision, considered the limitation of on-call hours as a factor to making their decision, and the exposure to Radiation played a role in making their decision. This is consistent with past work ${ }^{[15,16]}$ indicating that women are more relationship-oriented than men.

In the present work, most of females considering future pregnancy has affected decision. This agreed with other studies. ${ }^{[15-18]}$

There are some limitations to this study. First, the cross-sectional study design does not eliminate potential causal relationships between the motivational factors of medical students and Radiology career choice. Second, as a selfadministered questionnaire was utilized, some of the characteristics (such as motivational factors and choice of specialty) examined appeared to be more suitable for students in a higher academic year. third, the study measured students' interest in Radiology, but not their actual choice after graduation.

In conclusion, the present study showed a significant difference between male and female medical students in choosing Radiology as a future career. They differed somewhat in the importance they put on about motivational factors. Systematic improvements in the working environment are necessary to solve the low preference of Radiology as a future career among females

\section{References:-}

1. Center for workforce studies at the Association of American Medical Colleges (AAMC), 2012 physician specialty data book, AMCC, November 2012. Available from: https://members.aamc.org/eweb/upload/2012 Physician Specialty Data Book.pdf.

2. Center for workforce studies at the Association of American Medical Colleges (AAMC), 2008 physician specialty data, AMCC, November 2008. Available from: https://www.aamc.org/download/47352/data.

3. Fukuda Y, Harada T. Gender differences in specialty preference and mismatch with real needs in Japanese medical students. BMC Med. Educ. 2010; 10:15.

4. Fitzgerald JE, Tang SW, Ravindra P, Maxwell-Armstrong CA. Gender-related perceptions of careers in surgery among new medical graduates: results of a cross-sectional study. Am J Surg. 2013 Jul;206(1):112-9

5. Mwachaka1 P, Mbugua1 E. Specialty preferences among medical students in a Kenyan university. Pan Afr Med J. 2010; 5: 18. 
6. Diderichsen S, Johansson E, Verdonk P, Lagro-Janssen T, Hamberg K. Few gender differences in specialty preferences and motivational factors: a cross-sectional Swedish study on last-year medical students. BMC Med Educ. 2013; 13: 39.

7. Weissman C, Zisk-Rony RY, Schroeder JE, Weiss YG, Avidan A, Elchalal U, et al. Medical specialty considerations by medical students early in their clinical experience. Isr J Health Policy Res. 2012 Mar 12; 1(1):13.

8. Potterton VK, Ruan S, Sunshine JH, Applegate K, Cypel Y, Forman HP. Why don't female medical students choose diagnostic radiology? A review of the current literature. J Am Coll Radiol. 2004 Aug;1(8):583-90.

9. Baker SR, Barry M, Chaudhry H, Hubbi B. Women as radiologists: are there barriers to entry and advancement? J Am Coll Radiol. 2006 Feb;3(2):131-4.

10. Kawamoto R, Ninomiya D, Kasai Y, Kusunoki T, Ohtsuka N, Kumagi T, et al. Gender difference in preference of specialty as a career choice among Japanese medical students. BMC Med Educ. 2016; 16: 288.

11. Boulis AK, Jacobs JA. The changing face of medicine: women doctors and the evolution of health care in America Ithaca, N.Y. London: Cornell University ILR Press; 2008.

12. Riska E. Gender and medical career. Maturitas. 2011;68:264-7.

13. Goldacre MJ, Goldacre R, Lambert TW. Doctors who considered but did not pursue specific clinical specialties as careers: questionnaire surveys. J R Soc Med. 2012;105:166-76.

14. 14.. Enoch L, Chibnall JT, Schindler DL, Slavin SJ. Association of medical student burnout with residency specialty choice. Med Educ. 2013;47:173-81.

15. Fielding JR, Major NM, Mullan BF, Neutze JA, Shaffer K, Wilcox CB, et al. Choosing a specialty in medicine: female medical students and radiology. AJR Am J Roentgenol. 2007 Apr; 188(4):897-900.

16. Roubidoux MA, Packer MM, Applegate KE, Aben G. Female medical students' interest in Radiology careers. J Am Coll Radiol. 2009 Apr; 6(4):246-53.

17. Maj L, Baerlocher MO. Factors leading to radiology career selection: results of the 2004 National Physician Survey. Can Assoc Radiol J. 2006 Jun; 57(3):175-8.

18. Baerlocher MO, Walker M. Does gender impact upon application rejection rate among Canadian radiology residency applicants? Can Assoc Radiol J. 2005 Oct;56(4):232-7. 